Louisiana State University

LSU Digital Commons

5-1-2016

\title{
Correlates of sociometric status in Russian preschoolers: Aggression, victimization, and sociability
}

\author{
David A. Nelson \\ Brigham Young University \\ Kathryn C. Burner \\ Brigham Young University \\ Sarah M. Coyne \\ Brigham Young University \\ Craig H. Hart \\ Brigham Young University \\ Clyde C. Robinson \\ Brigham Young University
}

Follow this and additional works at: https://digitalcommons.Isu.edu/biosci_pubs

\section{Recommended Citation}

Nelson, D., Burner, K., Coyne, S., Hart, C., \& Robinson, C. (2016). Correlates of sociometric status in Russian preschoolers: Aggression, victimization, and sociability. Personality and Individual Differences, 94, 332-336. https://doi.org/10.1016/j.paid.2016.01.054

This Article is brought to you for free and open access by the Department of Biological Sciences at LSU Digital Commons. It has been accepted for inclusion in Faculty Publications by an authorized administrator of LSU Digital Commons. For more information, please contact ir@lsu.edu. 


\title{
Correlates of sociometric status in Russian preschoolers: Aggression, victimization, and sociability is
}

\author{
David A. Nelson *, Kathryn C. Burner, Sarah M. Coyne, Craig H. Hart, Clyde C. Robinson \\ School of Family Life, Brigham Young University, United States
}

\section{A R T I C L E I N F O}

\section{Article history:}

Received 21 August 2015

Received in revised form 29 January 2016

Accepted 31 January 2016

Available online 11 February 2016

\section{Keywords:}

Preschool children

Sociometric status

Aggression

Victimization

Russia

\begin{abstract}
A B S T R A C T
Few studies have assessed behavioral correlates of preschool children's peer sociometric status in cultures outside North America. This study focuses on 221 Russian preschoolers (108 boys, 113 girls). Correlates included physical and relational forms of aggression/victimization and sociable behavior. Confirmatory Factor Analyses (CFA) established that study instruments originally developed with U.S. preschoolers worked well in Russia. Findings in regard to aggression, sociability, and victimization were generally consistent with previous research with American and Italian preschoolers, particularly in regard to controversial status children. Our findings further challenge the notion that controversial children are consistently savvy in their social interactions. They and rejected children were most likely to be physically and relationally victimized by their peers.
\end{abstract}

(c) 2016 Elsevier Ltd. All rights reserved.

\section{Introduction}

Sociometric assessments measure children's peer status. Sociometric status groups are constructed using two factors: (a) how much a child is liked/disliked by peers (social preference) and (b) how well known the child is in the peer group (social impact; Nelson, Robinson, \& Hart, 2005). Children are categorized as popular (receiving many like nominations); rejected (many dislike nominations); controversial (many like and dislike nominations); neglected (few like or dislike nominations); and average (not meeting criteria for these other extreme groups). This taxometric approach has provided insight above and beyond consideration of the continuum of liking and disliking scores.

For example, researchers have long studied how sociometric status groups may uniquely differ in their social behaviors (Hymel, Vaillancourt, McDougall, \& Renshaw, 2002). Such differences have been identified as early as preschool (Nelson et al., 2005; Nelson, Robinson, Hart, Albano, \& Marshall, 2010) and help illuminate how children differentially navigate the demands of early peer interactions. Before sociometric status was considered, research studies generally found a significant positive correlation between aggression and peer rejection. Accordingly, aggression was universally considered as a risk

\footnotetext{
it This research was supported by grants from the Family Studies Center and the College of Family, Home, and Social Sciences at Brigham Young University, and the Zina Young Williams Card Professorship awarded to Craig H. Hart.

* Corresponding author at: School of Family Life, Brigham Young University, 2102C JFSB, Provo, UT 84602-6720, United States.

E-mail address: david_nelson@byu.edu (D.A. Nelson).
}

factor. The correlation was relatively modest, however, and obscured the fact that two types of children use high levels of aggression in their peer interactions: rejected and controversial status children. These children have different behavioral configurations and reputations.

In their meta-analytic review of sociometric status correlates, Newcomb, Bukowski, and Pattee (1993) found that sociometrically popular (universally liked) children tend to be sociable, cooperative, and engage in pleasurable peer interactions. Neglected children, in contrast, are withdrawn and unsociable. Rejected children are aggressive/ disruptive, with few appropriate social overtures. Controversial children have a unique behavioral reputation. They are usually as sociable as sociometrically popular children yet equally or more aggressive than rejected children, particularly in regard to relational aggression (e.g., Crick \& Grotpeter, 1995; DeRosier \& Thomas, 2003; Nelson et al., 2005). In short, controversial children have high social impact but polarize their peers in regard to social preference. This parallels findings of studies assessing the behavioral configurations of peer-perceived popular or bistrategic children in later developmental periods (e.g., Cillessen \& Mayeux, 2004; Hawley, 2003). In short, these terms all describe high-status children who deftly mix aggression and sociability to establish and maintain their status. Relational aggression is particularly important in this regard, as its frequently covert nature defies easy detection by parents and teachers.

Few studies have explored the correlates of sociometric status in preschool, particularly in cultures beyond North America. Nelson et al. (2010) considered the interplay of sociability and aggression (physical and relational) in predicting controversial status among Italian preschoolers. In addition, they assessed physical and relational subtypes of victimization, in order to determine whether controversial status 
children faced retribution for their often provocative nature. Findings showed that sociometrically popular children had pronounced sociability and low levels of aggression and victimization. Rejected status children had the opposite pattern. Neglected status children were not distinguished from average children. Finally, controversial children were highly aggressive and sufficiently sociable, and they invited the highest levels of both physical and relational victimization. The difference between controversial and rejected children was that sociable behavior buffered controversial children against wholesale peer rejection.

The purpose of the current study is to assess, for the first time, these associations in Russian preschoolers. A key question driving such research is whether the behavioral reputation of the controversial child is unique to Western samples (U.S. and Italy). Russia borders East and West and may not be fully consistent with the individualism that predominates many Western cultures. In particular, Russia may be more collectivist, following generations of Soviet communism. For decades, Soviet pedagogy promoted the values consistent with citizenship in a totalitarian socialist society, such as conformity, group-mindedness, and unquestioning obedience to authority (Hart, Nelson, Robinson, Olsen, \& McNeilly-Choque, 1998). Can the controversial status child be successful in establishing individual dominance in a culture that has long accentuated the collective over the individual? The controversial child seeks to stand out, and this may be inconsistent with the social tenets inspired by decades of communism.

To undertake this investigation, we must first identify potential behavioral correlates of sociometric status. Consistent with Bronfenbrenner's (1970) landmark study of Soviet childhood, physical and relational aggression are expected in Russian peer culture. Specifically, "... the children's collective became an agent of adult society and the major source of reward and punishment" (p.50) in seeking to instill communist values and behaviors. A child could be punished by the peer group via public criticism and potential exclusion from the group going forward. Accordingly, Soviet children were encouraged to harness the power of relational manipulation, consistent with the basic premise of relational aggression. Prior studies have investigated physical and relational aggression and victimization in Russian preschoolers (e.g., Hart et al., 1998, Hart et al., 2000), but this is the first study to address the social status correlates of such. Although aggression may not hold the exact same meaning across individualistic and collectivist cultures, we nonetheless expected this Russian sample to provide patterns similar to what have been obtained in the U.S. and Italy. In a collectivist culture, the controversial child needs to display adequate sociability to distract peers from his/her engagement in aggression. Greater social impact should also place the controversial child at risk of retribution from the peer collective, however.

\section{Study aims and hypotheses}

This study considers aggression, victimization, and sociability as they differentiate Russian preschoolers in sociometric status groups. First, we hypothesized that we would successfully identify these status groups with existing analytical procedures (described below). Second, prior research (Hart et al., 1998, 2000) has shown that aggression, victimization, and sociability can be reliably assessed in Russian preschoolers, using traditional measures (e.g., Cronbach's alpha, principal component factor analysis). We supplement prior research by employing SEM confirmatory factor analysis as a more stringent test of measurement adequacy. We verify that the observed variables, originally developed with Western datasets, are related in expected fashion with the underlying latent constructs.

Third, we provide our hypotheses for how behavioral reputations will reflect the various sociometric status extreme groups. Neglected children should evidence low levels of sociability, aggression, and victimization, consistent with their social obscurity. Sociometrically popular preschoolers were expected to show pronounced sociable behavior and low aggression and victimization. The opposite patterns apply to rejected children. The basic premise at work for popular and rejected children is that predominantly positive or negative behavior is related to peer social preference in expected ways. Finally, controversial status children should parallel rejected children in regard to levels of aggression and victimization, but differ by being sufficiently sociable.

\section{Method}

\subsection{Participants}

Participants included 221 children (108 boys, 113 girls) and their teachers in fifteen classrooms (mean of 17.2 children per classroom, range $=10$ to 29 ) in three nursery schools in Voronezh, Russia. These data are part of a larger study conducted in 1995, just after the dissolution of the U.S.S.R. The sample was $100 \%$ ethnic Russian as Voronezh was a sensitive military technology site during the Soviet period and foreigners were not allowed access to the city. The mean age of participating children was 60.23 months $(S D=8.54$; range from 44 to 79 months). Consent rate for the overall sample was approximately $86 \%$ (221/258). Teachers completed the teacher ratings and conducted the peer behavior nomination/sociometric assessments with each participating child.

Russian nursery schools traditionally act in loco parentis (meaning that the school takes all responsibility for in-school activities), and parents therefore did not give formal written permission for child participation (Hart et al., 1998). Instead, preschool administrators helped arrange parent meetings. Parents were assured of confidentiality of all data collected. If parents were against their child's participation, they successfully withdrew their child at this time. Parents of these preschoolers were generally well educated (means of $14.92(S D=2.34)$ and 14.5 ( $S D=2.42$ ) years for mothers and fathers, respectively; 12 years is equivalent to a high-school education).

\subsection{Measures}

All items described in this study were forward- and back-translated by Russian linguists.

\subsubsection{Peer behavior nominations}

Children were asked in individual interviews to identify classroom peers who are known for sociability and physical and relational aggression (time constraints imposed by preschool administrators did not allow for victimization data). We used a picture board nomination procedure (e.g., Asher \& Hymel, 1981) in which each participating child's picture was placed on a board. Children then pointed to the pictures of children who fit each behavioral descriptor (up to six classroom peers for each nomination item; see Table 1 for representative items). The number of nominations each child received for each item was standardized (z-scores) within each classroom.

\section{Table 1}

Standardized factor loadings for peer behavior nomination items.

\begin{tabular}{lll}
\hline Factor & Items & Loadings \\
\hline $\begin{array}{c}\text { Relational } \\
\text { aggression }\end{array}$ & $\begin{array}{l}\text { Who says, "I'm not going to be your friend anymore" } \\
\text { when they are mad or angry? }\end{array}$ & .90 \\
& $\begin{array}{l}\text { Who says, "don't play with that kid or you can't play } \\
\text { with us" when they are mad or angry? }\end{array}$ & .70 \\
Physical & Who pushes or hits a lot? & .89 \\
aggression & Who grabs toys or things away from other children? & .86 \\
& Who pushes other kids out of the way to get something & .87 \\
& they want? & .86 \\
Sociability & Who starts fights with other children? & .70 \\
& Who has lots of friends? & .58 \\
& Who takes turns and shares? & .96
\end{tabular}




\subsubsection{Peer sociometric assessments}

Using the picture board, children were asked to nominate three children with whom they like to play (positive nominations) and three children with whom they do not like to play (negative nominations). The sum of the positive nominations each child received from all peers represented Liking (L) scores, and the sum of negative nominations represented Disliking (D) scores. These scores were standardized within each class and then used to compute a Social impact (SI) score (L + D) and a Social preference (SP) score $(\mathrm{L}-\mathrm{D})$ for each child. Based on these scores (again standardized within classroom), and following a formula developed by Coie, Dodge, and Coppotelli (1982), children were classified into one of five sociometric status groups as follows: (a) popular ( $\mathrm{SP}>1.0 ; \mathrm{D}_{\mathrm{z}}<0 ; \mathrm{L}_{\mathrm{z}}>0$ ), (b) average ( $\mathrm{SP}>-.5$ and $\mathrm{SP}<.5$ ), (c) neglected ( $\left.\mathrm{SI}<-1.0: \mathrm{L}_{\mathrm{z}}<0 ; \mathrm{D}_{\mathrm{z}}<0\right)$, (d) rejected ( $\mathrm{SP}<-1.0$; $\left.\mathrm{D}_{\mathrm{z}}>0 ; \mathrm{L}_{\mathrm{z}}<0\right)$, and (e) controversial $\left(\mathrm{SI}>1.0 ; \mathrm{L}_{\mathrm{z}}>0 ; \mathrm{D}_{\mathrm{z}}>0\right)$. Children who did not fit into any category were considered average.

Prior studies of this nature have usually compared children not only by sociometric status but also explored potential gender-by-sociometric status differences. However, in this case, a prohibitively small group of controversial females precluded this possibility. Nonetheless, preliminary analyses showed no sex differences in mean comparisons and no sex-by-sociometric status interactions in the prediction of the various child behaviors/outcomes. Accordingly, we collapsed across gender in the analyses that follow. The resulting five groups were composed as follows: average (51\%), popular (16\%), neglected (14\%), rejected (12\%), and controversial (7\%).

\subsubsection{Teacher ratings}

Preschool teachers also completed a battery of measures that rated children's sociable and (physically and relationally) aggressive behaviors, as well as susceptibility to physical/verbal and relational victimization (see Table 2). All items were extensively pilot-tested and psychometrically evaluated in prior research (i.e., McNeilly-Choque, Hart, Robinson, Nelson, \& Olsen, 1996). Teachers rated children in response to items using a three-point scale anchored by never (1) and very often (3).

\section{Results}

\subsection{Confirmatory factor analyses}

The first step in analysis was to conduct two separate measurement models (confirmatory factor analyses; CFA) of the behavioral constructs obtained from peer behavior nominations and teacher ratings, respectively. These analyses were conducted in structural equation modeling (SEM) with the analysis of moments (AMOS) software. We also provide traditional reliability assessments for each of the constructs (i.e., Cronbach's alpha). For the peer nomination items (see Table 1), goodness of fit indices showed that the measurement model of the constructs represented the data well $\left(x^{2}=35.53, d f=24, p=.06, C F I=\right.$ $.99, T L I=.98, R M S E A=.04)$. Cronbach's alphas for all scales confirmed the CFA results, ranging from .77 to .93. In the CFA for the teacher-rated constructs (shown in Table 2), adequate model fit was also obtained $\left(x^{2}=284.23, d f=125, p<.001, C F I=.92, T L I=.90\right.$, RMSEA $\left.=.06\right)$. Cronbach's alphas for all teacher scales ranged from .72 to .89.

\subsection{Intercorrelations of study variables}

Next, we computed Pearson's correlations between all behavioral constructs. As seen in Table 3, the inter-informant correlations between peer-nominated and teacher-rated physical aggression, relational aggression, and sociability were modest yet significant. The strongest correlations are found in the teacher ratings, between aggression subtypes and victimization.

\subsection{Assessing mean levels of social behaviors by sociometric status}

The primary analyses for this study concern sociometric status differences in the behaviors of interest (aggression, victimization, and sociability). Accordingly, a MANOVA was conducted in which sociometric status was the between-subjects factor and all peer-nominated and teacher-rated behavioral scores were simultaneously entered as dependent variables. Given an unequal $n$ design (in the number of children across the various sociometric status groups), the following analyses are based on GLM comparisons of the unweighted means (estimated marginal means). See Table 4 for the means and standard deviations of all sociometric status group comparisons. The effect sizes (Cohen's $d$ ) for the comparison of the respective sociometric extreme group with the average group allow comparison with analogous effect sizes reported by Newcomb et al. (1993).

Results of the MANOVA analysis showed a significant multivariate effect for sociometric status (Wilks' Lambda $=.31, p<.001$ ). At the univariate level, significant group differences were evident for all behavioral scales except teacher-rated relational aggression. First, a significant main effect of sociometric status in the prediction of peer-nominated relational aggression $\left(F(4,206)=3.11, p<.05\right.$, partial $\left.\eta^{2}=.06\right)$ showed that controversial and rejected children engaged in the highest levels of relational aggression, although rejected children did not differ from average or popular children in this regard. Neglected and average children enacted the least relational aggression.

For the significant effect in the prediction of peer-nominated physical aggression $\left(F(4,206)=27.80, p<.001\right.$, partial $\left.\eta^{2}=.35\right)$, rejected

Table 2

Standardized factor loadings for teacher rating items.

\begin{tabular}{|c|c|c|}
\hline Factor & Items & Loadings \\
\hline \multirow[t]{5}{*}{ Relational aggression } & Tells a peer that he/she won't play with them if he/she doesn't do what is asked. & .83 \\
\hline & Says, "I won't be your friend" to peers "if you won't do things my way. & .82 \\
\hline & Tells other children that they can't play with the group unless they do what the group wants them to do. & .78 \\
\hline & Threatens to keep a peer out of the play group if the peer doesn't do what the child says. & .74 \\
\hline & Tells other children not to play with or be a peer's friend. & .71 \\
\hline \multirow[t]{3}{*}{ Physical aggression } & Threatens to push a peer off a toy (e.g., tricycle, play house) or ruin what peer is working on unless he/she shares. & .83 \\
\hline & Ruins other children's things (artwork, block structures) when upset. & .73 \\
\hline & Throws things at other children when he/she doesn't get his/her own way. & .71 \\
\hline \multirow[t]{3}{*}{ Physical/verbal victimization } & Is made fun of by mean kids. & .76 \\
\hline & Is picked on by mean kids. & .64 \\
\hline & Is pushed around by other children. & .59 \\
\hline \multirow[t]{4}{*}{ Relational victimization } & Other children seem unwilling to play with this child. & .87 \\
\hline & Is told to go away by other children. & .81 \\
\hline & Other children exclude him/her. & .80 \\
\hline & Other children tell him/her that he/she cannot play with them. & .79 \\
\hline \multirow[t]{3}{*}{ Sociability } & Likes to talk with peers. & .82 \\
\hline & Has many friends. & .82 \\
\hline & Can get activities going with other children. & .70 \\
\hline
\end{tabular}


Table 3

Descriptive statistics and intercorrelations of study variables.

\begin{tabular}{|c|c|c|c|c|c|c|c|c|}
\hline & 1 & 2 & 3 & 4 & 5 & 6 & 7 & 8 \\
\hline Mean & .00 & .00 & .00 & 2.41 & 1.94 & 1.54 & 1.40 & 2.46 \\
\hline$S D$ & .88 & .89 & .81 & .40 & .40 & .43 & .49 & .54 \\
\hline 1. Relational aggression $(\mathrm{P})$ & - & $.38^{* * *}$ & .10 & $.20^{* *}$ & $.22^{* * * *}$ & .10 & .12 & .01 \\
\hline 2. Physical aggression (P) & & - & $-.16^{* *}$ & $.17^{*}$ & $.32^{* * *}$ & $.16^{*}$ & $.27^{* * *}$ & $-.18^{* *}$ \\
\hline 3. Sociability $(\mathrm{P})$ & & & - & -.03 & $-.15^{*}$ & $-.14^{*}$ & $-.21^{* *}$ & $.28^{* * *}$ \\
\hline 4. Relational aggression $(\mathrm{T})$ & & & & - & $.54^{* * *}$ & $.33^{* * *}$ & $.39^{* * *}$ & .04 \\
\hline 5. Physical aggression (T) & & & & & - & $.42^{* * * *}$ & $.57^{* * * *}$ & $-.14^{* *}$ \\
\hline 6. Physical/verbal victimization ( $\mathrm{T}$ ) & & & & & & - & $.56^{* * *}$ & $-.22^{* * *}$ \\
\hline 7. Relational victimization (T) & & & & & & & - & $-.48^{* * *}$ \\
\hline 8. Sociability (T) & & & & & & & & - \\
\hline
\end{tabular}

Note. ${ }^{*} p<.05 ;{ }^{* *} p<.01 ;{ }^{* * *} p<.001$. P: peer nomination scales; T: teacher rating scales.

and controversial children were clearly engaged in very high levels of physical aggression, compared with all other status groups. Neglected and popular children engaged in the least physical aggression, and average children were in the middle (though not significantly different from popular children). Finally, in regard to peer nominations of sociability, the significant main effect $\left(F(4,206)=32.65, p<.001\right.$, partial $\eta^{2}=$ .39) showed popular children to be viewed as highly sociable, greater than all other status groups. Controversial and average children were in the next tier, and neglected and rejected children were in the lowest tier (significantly different from all other groups).

In regard to teacher-rated physical aggression, the main effect of sociometric status $\left(F(4,206)=2.78, p<.05\right.$, partial $\left.\eta^{2}=.05\right)$ showed rejected children highest and no different from controversial children. Controversial children were in turn no different from average children, but significantly higher in physical aggression than popular and neglected children. Second, the main effect for teacher-rated sociability $\left(F(4,206)=6.31, p<.001\right.$, partial $\left.\eta^{2}=.11\right)$ showed that popular and neglected children were considered higher in sociability than all other status groups (which were no different from each other).

Third, the teacher-rated physical/verbal victimization main effect $\left(F(4,206)=2.47, p<.05\right.$, partial $\left.\eta^{2}=.05\right)$ showed that rejected and controversial status children were highly victimized relative to neglected children, but these groups did not differ significantly from

Table 4

Means and standard deviations by sociometric status.

\begin{tabular}{llllll}
\hline Peer ratings & \multicolumn{3}{l}{ Sociometric status } & & \\
\cline { 2 - 6 } & Average & Popular & Neglected & Rejected & Controver. \\
\hline PN relational aggression & $.00^{\mathrm{ab}}$ & $.15^{\mathrm{bc}}$ & $-.36^{\mathrm{a}}$ & $.27^{\mathrm{bc}}$ & $.49^{\mathrm{c}}$ \\
(SD) & $(.91)$ & $(.89)$ & $(.88)$ & $(.94)$ & $(.88)$ \\
Effect size & & .17 & -.40 & .29 & .55 \\
PN physical aggression & $-.14^{\mathrm{b}}$ & $-.32^{\mathrm{ab}}$ & $-.50^{\mathrm{a}}$ & $1.20^{\mathrm{c}}$ & $.90^{\mathrm{c}}$ \\
(SD) & $(.75)$ & $(.74)$ & $(.75)$ & $(.78)$ & $(.74)$ \\
Effect size & & -.24 & -.48 & 1.75 & 1.40 \\
PN sociability & $.05^{\mathrm{b}}$ & $1.09^{\mathrm{c}}$ & $-.45^{\mathrm{a}}$ & $-.64^{\mathrm{a}}$ & $.24^{\mathrm{b}}$ \\
(SD) & $(.68)$ & $(.66)$ & $(.67)$ & $(.70)$ & $(.66)$ \\
Effect size & & 1.55 & -.74 & -1.00 & .28 \\
TR relational aggression & $2.42^{\mathrm{a}}$ & $2.34^{\mathrm{a}}$ & $2.32^{\mathrm{a}}$ & $2.51^{\mathrm{a}}$ & $2.51^{\mathrm{a}}$ \\
(SD) & $(.40)$ & $(.40)$ & $(.40)$ & $(.40)$ & $(.40)$ \\
Effect size & & -.20 & -.25 & .22 & .22 \\
TR physical aggression & $1.93^{\mathrm{ab}}$ & $1.84^{\mathrm{a}}$ & $1.84^{\mathrm{a}}$ & $2.11^{\mathrm{c}}$ & $2.10^{\mathrm{bc}}$ \\
(SD) & $(.39)$ & $(.40)$ & $(.39)$ & $(.39)$ & $(.40)$ \\
Effect size & & -.22 & -.23 & .46 & .43 \\
TR sociability & $2.38^{\mathrm{a}}$ & $2.76^{\mathrm{b}}$ & $2.63^{\mathrm{b}}$ & $2.28^{\mathrm{a}}$ & $2.29^{\mathrm{a}}$ \\
(SD) & $(.51)$ & $(.51)$ & $(.51)$ & $(.51)$ & $(.52)$ \\
Effect size & & .75 & .49 & -.20 & -.17 \\
TR physical victimization & $1.55^{\mathrm{ab}}$ & $1.45^{\mathrm{ab}}$ & $1.40^{\mathrm{a}}$ & $1.65^{\mathrm{b}}$ & $1.69^{\mathrm{b}}$ \\
(SD) & $(.43)$ & $(.43)$ & $(.42)$ & $(.43)$ & $(.42)$ \\
Effect size & & -.23 & -.35 & .23 & .33 \\
TR relational victimization & $1.41^{\mathrm{bc}}$ & $1.15^{\mathrm{a}}$ & $1.30^{\mathrm{ab}}$ & $1.57^{\mathrm{cd}}$ & $1.78^{\mathrm{d}}$ \\
$(S D)$ & $(.47)$ & $(.47)$ & $(.47)$ & $(.47)$ & $(.47)$ \\
Effect size & & -.55 & -.23 & .34 & .79 \\
\hline
\end{tabular}

Note. ${ }^{\text {abc }}$ Means in the same row not sharing a superscript differ at $p<.05$ using Fisher's LSD test; PN = peer-nominated; TR = teacher-rated. Effect sizes are Cohen's d for each extreme group vs. average. popular or neglected children. Fourth, the main effect for teacherrated relational victimization $\left(F(4,206)=6.95, p<.001\right.$, partial $\eta^{2}=$ .12 ) found rejected and controversial children as the most relationally victimized, with controversial status children rated higher than all remaining status groups. Popular and neglected children experienced the least relational victimization.

\section{Discussion}

The purpose of this study was to assess the behavioral correlates (enacted or received) of sociometric status for Russian preschoolers. The Western-derived measures showed utility in measuring important behavioral constructs, which accordingly represent fundamental social experiences for Russian preschoolers (see also Hart et al., 1998, 2000). Confirmatory factor analysis of the measures particularly strengthened our contention that the various constructs could be reliably distinguished.

At the correlational level (see Table 3), strong correlations between aggression and victimization subtypes suggest that Russian teachers considered many aggressive preschoolers to both give and receive aggressive acts (consistent with the notion of bully/victims; Olweus, 1993; Schwartz, Dodge, Pettit, \& Bates, 1997). It is also notable that relational aggression is uncorrelated with sociability (for both teacherand peer-reports) in this study. Accordingly, the interplay between sociability and aggression is only detected when one considers the behavioral profiles of the various sociometric status groups.

There are also substantial negative correlations between teacher perceptions of sociability and both subtypes of victimization (particularly relational victimization). Apparently, those who struggle to appropriately engage socially with peers are more likely the target of relationally aggressive acts. Alternately, victimization likely leads to greater withdrawal from social interactions. Accordingly, interventions that involve social skills training may be useful in helping victimized peers to be more demonstrative in social situations and build confidence to engage positively with others and to avoid social isolation.

Looking at mean levels (see Table 3), it is striking that Russian preschool teachers perceived relational aggression to happen just as frequently as sociable behavior (an average frequency halfway between "sometimes" and "always"). Accordingly, relational aggression appears to be normative in the minds of Russian preschool teachers. Sociometric status analysis also provided no significant differences between groups in regard to teacher ratings of relational aggression. This suggests that Russian preschool teachers see children uniformly engaged in fairly high levels of relational aggression. We can only speculate as to why Russian preschool teachers view relational aggression as so pervasive. Observational studies are needed to document whether Russian preschoolers actually engage in high levels of relational aggression or if Russian teachers are somehow primed to see this behavior more consistently than teachers in other cultures.

As noted earlier, under decades of communism, the peer group was a significant source of punishment for individuals whose behavior misaligned with Soviet ideals. The teachers in this study matured in 
such a society. Accordingly, peer group relational aggression may be normative in the minds of teachers, and teachers may not be as attuned to individual differences in relational aggression. These data were also collected soon after the fall of the Soviet Union, so the vestiges of Soviet culture may not have ebbed much. However, it is important to keep in mind that Russian peers and teachers only modestly correlated in their perceptions of aggression. Peers were able to differentiate controversial children as high on relational aggression compared with other status groups, but the effect was still modest (partial $\eta^{2}=.06$ ). Observational studies may again be an important avenue to further investigate the actual prevalence of relationally aggressive behavior in Russian preschools.

In regard to the multivariate findings, the multi-informant findings with Russian preschoolers (aggression and sociability) generally paralleled the findings of earlier studies with U.S. and Italian preschoolers. Of particular interest is the pattern of findings for controversial status children, who are again generally perceived as adequately sociable yet highly aggressive, particularly in regard to relational aggression (see Table 4). Accordingly, a small group of preschoolers (7\% in this Russian sample) appear to be adept at mixing sociability and aggression in their bid to attain and maintain significant social status. This pattern has now been established in preschoolers in three different cultures. Future studies will want to further pursue these associations with Asian samples to further test the universality of these associations.

Regarding teacher ratings of victimization, rejected and controversial children were perceived as the most frequent targets of relational victimization (less discrimination was evident with physical/verbal victimization; see Table 4). Thus, although Russian teachers saw no group differences in relational aggression, they did see rejected and controversial children as the most likely to be targeted in this manner. This parallels victimization findings with an Italian preschool sample (Nelson et al., 2010). Our findings further challenge the notion that controversial status children consistently benefit from skillful combinations of affiliative and dominance-oriented behaviors. They also encounter high levels of victimization by others, just like rejected children.

The current study offers valuable confirmatory insights into the social worlds of Russian preschoolers. Further research will enhance our understanding. First and foremost, a larger sample would provide opportunity to consider both sex of child and sociometric status in the consideration of all of these behaviors, as well as greater statistical power to detect such effects. It would also be useful to conduct additional studies with preschoolers which capture a greater range of behaviors and relational contexts. Hawley, Little, and Card (2007) have shown, for example, that bistrategic controllers (essentially equivalent to controversial status children) in the middle-school years tend to have best friendships that are high in intimacy and fun, but also conflict (yielding both high benefits as well as costs). It might be insightful to probe the friendships of controversial preschoolers in this regard, giving insight into how controversial children succeed in maintaining significant social status as relational contexts combine in their influence.

Although the CFAs suggested that the Western-based observed items appeared to work well in Russia, there are potentially indigenous understandings of relational aggression (and other behaviors) that cannot be tapped with preexisting measures. In short, further research is necessary to probe how relational aggression and other social behaviors may occur in the Russian cultural context so that culturally sensitive items might be developed to better measure constructs of interest. It is possible, of course, that many relational aggressive behaviors are more or less universal. But culturally sensitive work is needed to test this assumption. Additional research will also help illuminate whether preschool relationships in Russia have been altered in the last two decades, as Russian families and society have been potentially influenced by greater openness to cultures beyond Russia's borders.

In conclusion, this study suggests that preschoolers in the Russian cultural context appear to act much like their peers in Western samples, and those behaviors inform social status in expected ways. Of particular interest is the behavior of controversial children (Hawley et al., 2007). Accordingly, Russian teachers may benefit from educational efforts to help them identify controversial or rejected children, and engage in social coaching efforts which may help diminish the prevalence and impact of aggressive behaviors in the classroom. Addressing these issues early, in the preschool years, is particularly important as these are the years of greatest neurological and psychological malleability. This may lead to welcome change and better peer opportunities for all children.

\section{References}

Asher, S.R., \& Hymel, S. (1981). Children's social competence in peer relations: Sociometric and behavioral assessment. In J.D. Wine, \& M.D. Smye (Eds.), Social competence (pp. 125-157). New York: Guilford Press.

Bronfenbrenner, U. (1970). Two worlds of childhood: U.S. and U.S.S.R. New York: Russell Sage Foundation.

Cillessen, A.H.N., \& Mayeux, L. (2004). From censure to reinforcement: Developmental changes in the association between aggression and social status. Child Development, $75,147-163$.

Coie, J.D., Dodge, K.A., \& Coppotelli, H. (1982). Dimensions and types of status: A cross-age perspective. Developmental Psychology, 18, 557-570.

Crick, N.R., \& Grotpeter, J.K. (1995). Relational aggression, gender, and socialpsychological adjustment. Child Development, 66, 710-722.

DeRosier, M.E., \& Thomas, J.M. (2003). Strengthening sociometric prediction: Scientific advances in the assessment of children's peer relations. Child Development, 75 1379-1392.

Hart, C.H., Nelson, D.A., Robinson, C.C., Olsen, S.F., \& McNeilly-Choque, M.K. (1998). Overt and relational aggression in Russian nursery-school-age children: Parenting style and marital linkages. Developmental Psychology, 34, 687-697.

Hart, C.H., Nelson, D.A., Robinson, C.C., Olsen, S.F., McNeilly-Choque, M.K., Porter, C.L., \& McKee, T.R. (2000). Russian parenting styles and family processes: Linkages with subtypes of victimization and aggression. In K.A. Kerns, J.M. Contreras, \& A.M. NealBarnett (Eds.), Family and peers: Linking two social worlds (pp. 47-84). Westport, CT: Praeger Publishers.

Hawley, P.H. (2003). Strategies of control, aggression, and morality in preschoolers: An evolutionary perspective. Journal of Experimental Child Psychology, 85, 213-235.

Hawley, P.H., Little, T.D., \& Card, N.A. (2007). The allure of a mean friend: Relationship quality and processes of aggressive adolescents with prosocial skills. International Journal of Behavioral Development, 31, 170-180.

Hymel, S., Vaillancourt, T., McDougall, P., \& Renshaw, P. (2002). Peer acceptance and rejection in childhood. In P.K. Smith, \& C.H. Hart (Eds.), Blackwell handbook of childhood social development (pp. 265-284). Oxford: Blackwell Publishers, Ltd.

McNeilly-Choque, M.K., Hart, C.H., Robinson, C.C., Nelson, L.J., \& Olsen, S.F. (1996). Overt and relational aggression on the playground: Correspondence among different informants. Journal of Research in Childhood Education, 11, 47-67.

Nelson, D.A., Robinson, C.C., \& Hart, C.H. (2005). Relational and physical aggression of preschool-age children: Peer status linkages across informants. Early Education and Development: Special Issue on Relational Aggression in Early Childhood, 16, 115-139.

Nelson, D.A., Robinson, C.C., Hart, C.H., Albano, A.D., \& Marshall, S.J. (2010). Peer interactions among Italian preschoolers: Peer-status linkages with physical and relational aggression and victimization. Social Development, 19, 698-720.

Newcomb, A.F., Bukowski, W.M., \& Pattee, L. (1993). Children's peer relations: A metaanalytic review of popular, neglected, controversial, and average sociometric status. Psychological Bulletin, 113, 99-128.

Olweus, D. (1993). Bullies on the playground: The role of victimization. In C.H. Hart (Ed.), Children on playgrounds: Research perspectives and applications (pp. 85-128). Albany, NY: State University of New York Press.

Schwartz, D., Dodge, K.A., Pettit, G.S., \& Bates, J.E. (1997). The early socialization of aggressive victims of bullying. Child Development, 68, 665-675. 